\title{
Comparative Study of two Kalman Algorithms for Estimating the State of Charge of Lithium-Ion Cells at Ambient Temperature
}

\author{
Fuwu Yan ${ }^{1,2}$, Chi Zhang ${ }^{1,2}$, Changqing Du ${ }^{1,2}{ }^{*}$ and Ching-Hsiang Cheng ${ }^{1,2}$ \\ ${ }^{1}$ Hubei Key Laboratory of Advanced Technology for Automotive Components (Wuhan University of \\ Technology), Wuhan 430070, China; \\ ${ }^{2}$ Hubei Collaborative Innovation Center for Automotive Components Technology, Wuhan 430070, \\ China; \\ *E-mail: cq_du@whut.edu.cn
}

doi: $10.20964 / 2018.12 .65$

Received: 31 August 2018 / Accepted: 8 October 2018 / Published: 5 November 2018

Kalman filters (KFs) are effective tools for estimating online state of charge (SOC), and a great variety of studies about different kinds of KFs have been published. However, problems remain in this field. First, the impact of ambient temperature on the internal parameters of equivalent circuit models (ECM) are seldom discussed. Second, comparative studies about different KFs are not fully validated under different conditions. To solve these problems, a modified equivalent circuit model was developed. The model was proposed to serve in ambient temperature and the usage of the total available capacity. Two typical nonlinear KFs, namely, the extended and unscented KFs were applied in SOC estimation. The model parameters were identified by hybrid pulse power characterization tests at $0,15,30,45$, and 55 ${ }^{\circ} \mathrm{C}$. Meanwhile, the algorithms were validated under self-designed federal urban driving schedule sequence profiles at $0,10,20,30,40$, and $50{ }^{\circ} \mathrm{C}$ with the same tuning setups. The robustness of the algorithm was also investigated in terms of voltage sensor uncertainty and the initial SOC offset. Results indicated that the proposed model can achieve the minimum mean absolute error and root mean squared error with the unscented KF at all test conditions.

Keywords: Equivalent circuit model; Kalman filter; State of charge estimation; Temperature modeling; Lithium-ion battery

\section{$\underline{\text { FULL TEXT }}$}

(C) 2018 The Authors. Published by ESG (www.electrochemsci.org). This article is an open access article distributed under the terms and conditions of the Creative Commons Attribution license (http://creativecommons.org/licenses/by/4.0/). 